\title{
Introduction: fiscal federalism - a review of developments in the literature and policy
}

\author{
Ehtisham Ahmad and Giorgio Brosio
}

\section{Motivation}

This Handbook addresses fiscal relations between different levels of government under the general rubric of 'fiscal federalism'. While the study of federal systems is an important part of the volume, it also covers other forms of intergovernmental relations. This ranges from unitary states, regional systems, to more decentralized operations, including community-level organizations, and federal systems through to supranational constructs (such as the European Union: EU). The volume seeks to provide a review of the latest literature on the broad subject of fiscal federalism, and also to guide practitioners and policy makers seeking informed policy options.

In the case of intergovernmental relations, the recent evolution of theory has been rapid and substantial. The traditional, largely normative, approach was based on the assumption of a benevolent government. Much of the recent literature drops this assumption and takes governments and politicians and officials as self-interested players. Thus, the normative approach has largely given way to a political economy approach. The latter emphasizes the importance of institutional arrangements, including the legal, political and administrative aspects, and information flows to ensure that there are appropriate incentives and sanctions to generate good governance. The volume, thus, has a combination of analytical and policy-oriented contributions.

The diffusion of federal or decentralized arrangements across the world, including changes in supranational arrangements, has been equally rapid. There have been reactions to excessive centralization in some unitary states, such as Indonesia, that have led to demands for greater responsibilities or resources for regional or local government, if not federalism. In unitary states such as Spain and Italy, quasi-federal constructs have been adopted. While this volume does not include country studies, the choice of the chapters and their content reflects the trends and policy questions that are apparent across the globe.

In countries with an established and strong legal framework, new institutional approaches, such as the diffusion of asymmetric arrangements, have emerged. There are also new relationships between governments, such as contractual agreements. The Handbook provides an account of this evolution. 


\section{Handbook of fiscal federalism}

Clearly, intergovernmental fiscal relations pose different challenges according to the distinct economic and societal characteristics of each country. In developing countries, decentralization has been promoted by some multilateral agencies and bilateral donors as an instrument for improving service delivery in sectors that are crucial for the alleviation of poverty. Poverty reduction is a new and crucial task for decentralized systems. It is not exclusively a developing-country issue, but mirrors the policy debates in industrial countries where poverty reduction has shifted from local governments to higher-level programmes, usually at the central level, for social security for the aged and disabled and unemployment insurance for the unemployed. Successful decentralization that leads to improvements in public service delivery and poverty reduction requires substantial reforms to improve governance, such as transparency of government operations and the provision of information. Consequently, these practical considerations require an adaptation of the theory, as shown in the chapters of this volume dealing with the design of intergovernmental systems. However, in all countries the decentralization process poses a challenge for maintaining sustainable macroeconomic conditions.

The evolution of federal and decentralized systems has been paralleled by the emergence of new issues, such as environmental protection, the sharing of natural resources among levels of government, corruption and the impact of federalism and decentralization on national unity. The Handbook also provides chapters on these topics.

The Handbook is structured as follows. Part I deals with the different approaches to fiscal federalism. Ben Lockwood examines the political economy aspects. Chapters by Pierre Salmon and Albert Breton address the vertical and horizontal aspects of federalism and competition. Federico Revelli examines issues related to spatial interactions across governments. We then have three chapters on aspects of contractual approaches to decentralization. Roger Congleton's addresses asymmetric federalism, and Reiner Eichenberger and Bruno Frey review the literature on 'functional, overlapping and competing jurisdictions' (FOCJ) to which they have made seminal contributions. Paul Bernd Spahn then reviews the important and growing area of contract federalism.

Part II deals with decentralization and development, with a review of the issues and literature by Pranab Bardhan. Govinda Rao addresses the process of decentralization in countries that have been subject to central or development planning. Partly based on their work in the World Bank's World Development Report on Service Delivery, Junaid Ahmad, Shantayanan Devarajan, Stuti Khemani and Shehkar Shah address the interactions between decentralization and service delivery.

Part III is devoted to the design and implementation of multilevel systems. Bernard Dafflon provides a comprehensive discussion of the expenditure 
assignments issue. Flavia Ambrosanio and Massimo Bordignon provide the equivalent discussion on revenue assignments and administrative constraints. As tax competition is an important determinant of revenue assignments, we next have a survey of this area by John Wilson. Given expenditure and revenue assignments, we next address the need for transfers to subnational governments. Robin Boadway examines the equity and efficiency considerations that could underpin the design of transfer systems. Ehtisham Ahmad and Bob Searle address how transfer systems might be implemented. The increasingly important issues of governance and management of the public finances, including the overall macroeconomic considerations, are surveyed by Ehtisham Ahmad, Maria Albino-War and Raju Singh.

Part IV is devoted to important emerging issues and contains an eclectic collection. In many countries, the control over natural resources poses considerable challenges to national unity, and price and quantity variability threatens the smooth management of the economy, particularly at the subnational level. Giorgio Brosio examines this issue, the scope for possible assignments of natural resource revenues to subnational governments, and the pros and cons of more generalized sharing of natural resources.

Environmental issues are also increasingly at the fore of the policy and analytical discussion, and Silvana Dalmazzone provides an example of how such matters might be analysed - focusing largely on the mechanisms needed at different levels of government to control pollution.

Anwar Shah reviews the possible links between corruption and decentralization - surveying a growing and somewhat contentious literature. Richard Bird and Robert Ebel address the issues involved in keeping countries together in the face of sharp ethnic and cultural divides which permeate many societies.

Finally, we present a political scientist's approach to fiscal federalism with Brian Galligan's chapter on institutions and decentralized governments.

The evolution of the literature has led to substantive changes in the approaches to fiscal federalism, and in the coverage of associated issues. The editors' choices have been challenging, the aim of this Handbook is to cover the literature, and to provide the reader with new avenues for exploring the field in terms of both the analytical approaches and policy relevance. Further elaboration of these issues and chapter summaries follow.

\section{Approaches to fiscal federalism}

The genesis of fiscal federalism and the normative perspective

Federal systems have been in existence at least since the American Revolution and independence. The text drafted by the convention at Philadelphia in 1787 provides the first example of a modern federal constitution (see Madison et al. 1788). As is frequently the case with most theories, the literature on fiscal 
federalism has been strongly influenced by the geo-political context in which it originated; namely, the federal systems of North America. This has led to problems relating to its extension to other cases, especially to the nation states of Europe and Asia. A simple example refers to the assignment problem. Fiscal federalism theory (see, for example, Musgrave 1961; Olson 1969) dictates that responsibilities should be assigned according to the equivalence principle, or that the jurisdiction responsible for a given public policy should coincide with the geographic coverage of the impact of these policies on households and the relevant electorate. This presupposes that subnational jurisdictions can be created, merged or modified at practically zero cost.

The creation of new government units has been a common practice in North America, where there is still a possibility of extending the coverage of public services, incorporating new territory to create new jurisdictions. This is generally not possible for most Asian or European local governments - the main units for the operation of decentralized systems. Cities with the same rank in terms of their political or spatial hierarchy - for example, district, province, or regional capitals - tend to have a huge variance in terms of size of area, of population, and of wealth and economic specialization. On the basis of the equivalence principle, it would be hard to deny to the smallest or weakest jurisdictions at a given level the powers that theory considers appropriate for the biggest and most capable ones.

The past half-century or so has seen a significant pressure and move towards decentralization or federalization all over the world. The decentralization process has rendered the study of fiscal federalism more relevant in a policy context, and there has been a parallel development of economic method and analysis in tandem with most of the institutional changes that have taken place. For example, a frequent occurrence has been the creation of regions through the insertion of a new level of administration between the centre and local governments. Regional systems do not fit well within the mainstream theory of fiscal federalism, which has focused largely on choices between federal and unitary systems. Regional systems have developed very different institutions, and it is hard to portray a universal type.

More than forty years have elapsed since economists formally addressed the theory of fiscal federalism and the working of subnational government units. Richard Musgrave's definition of fiscal federalism as a system whose purpose 'is to permit different groups living in various states to express different preferences for public services; and this, inevitably, leads to differences in the levels of taxation and public services' appeared in 1959 (Musgrave 1959, p. 179). The Tiebout (1956) model also provided an underpinning of the literature for several decades. Mancur Olson's seminal contribution to this literature - namely, the principle of equivalence - was published in 1969. Wallace Oates (1972) presented the first systematization three years later. 
The early literature on fiscal federalism was characterized by a strong normative flavour, which pervaded economic discipline at the time. Since, by hypothesis, governments are run by benevolent policy makers intending to maximize the welfare of their communities, government failures cannot derive from the deviant behaviour of rulers or governing elites intent on pursuing their personal interest, but only from lack of expertise and knowledge. For example, spillovers generated by local government operations could be addressed by earmarked grants administered by the central government. Thus the central government would ensure full internalization of spillovers, while decentralization will accomplish preference matching. In fact neither conclusion is warranted. Central governments may be able to vary policies to meet local preferences, but may not be able to ensure internalization of spillovers generated by local governments (Breton 1965).

When applied to bottom-up processes of federalization, such as the European Union, fiscal federalism theory has not been up to the challenge, because of missing political economy considerations. Defence and foreign policy have not been reassigned to the European level, contrary to every dictate of the theory, simply because European governments and citizens are strongly attached to vestiges of national identity and security.

\section{Political economy approaches versus benevolent policy makers?}

As stated by Ben Lockwood in Chapter 1, assuming benevolent policy makers amounts to modelling government as a black box, in which meaningful political institutions are absent. Benevolent rulers could be replaced by personally motivated policy-makers and associated institutions. The political economy literature, for instance, has developed the interplay of a national legislature and a set of locally elected policy makers. Modelling of politics and institutions is still relatively simplified and partial. A substantive advance has been to introduce accountability as an issue - which did not exist as a problem in a framework based on a premise of benevolent policy makers. Positive approaches assume that with interested policy makers, measures will be needed to address the absence of accountability in its various forms.

Chapter 1 provides a comprehensive review of the literature on decentralization based on the political economy approach. Lockwood models the behaviour of governments, whether at the national or local levels, taking into account actual institutions and processes, such as elections and legislatures. The chapter starts with a large component of this literature, the legislative models. The legislature, whose representatives have conflicting interests over regional public goods provision, makes the decisions on centralized functions. The results are then compared with those of a decentralized system. The analysis shows that with decentralization there is better matching to preferences, implying a larger consumer surplus than with a centralized government. This 
holds both in the case where citizens have identical preferences within each region, and also in the case where there is non-homogeneity of preferences in the regions.

A second important result concerns accountability. There are at least two meanings of this concept. The first relates to whether institutions allow politicians or officials to misuse public funds for their own purposes. The second refers to the distortions exerted by lobbies on resource allocation. There are three reasons why a decentralized government reduces rent diversion. The first is simply a scale effect. In a centralized setting, the size of total rent is higher, thus creating more inducements for diversion. The second reason is the reduction in the probability that voters will be pivotal in determining the outcome of the national election. In turn, this reduces the inducement for elected officials to implement the imperfect contract they have with their electors. A third reason is enhanced competition, which is dealt with at length in the following chapters by Salmon, Breton and Revelli.

Some or most of the results on the political economy of decentralization could be reversed if lobbies function in a decentralized system. James Madison had warned against capture by 'factions' at the local level in the Federalist Papers. The results of modern political economy models are less conclusive, but there is a prevalence of views that centralized government can reduce the distorting power of the lobbies, provided that specific conditions are met. These include provision that the national legislature be elected according to proportional representation, circulation of more accurate and timely information on the sources and uses of public funds, and managed or restricted organization of lobbies at the central level.

Thus, the support in the political economy context for decentralization remains a qualified one.

\section{Decentralization and competition}

Competition has generally been recognized as one of the biggest merits of decentralized government. The argument has originally been advanced in the Federalist Papers where it was argued that the federal entity created by the (American) constitution would introduce a vertical separation of powers that would complement a horizontal separation. Since Montesquieu (1914), separation of powers in the public sphere essentially refers to competition, and that citizens would have more alternatives for fulfilling their aspirations. When they perceive themselves to be disadvantaged by a decision of the executive, they can turn to the judiciary to overturn the decision, or for compensation, and vice versa, or they can address issues to the legislative power. In a decentralized setting, they also have the alternative of addressing either the central and/or their local government, or of voting with their feet. This is reflected in the traditional Tiebout (1956) approach to decentralized 
government - competition is driven by mobility of citizens/consumers of public services. Citizens and consumers move their residence to those jurisdictions that provide them with the quantity and quality of services that they are looking for at the lowest cost, especially in terms of taxation.

In turn, competition ensures the matching of provision of services with local preferences, and inefficiency is minimized. Although this process of competition has been labelled 'voting with one's feet', there is actually no politics in this model.

Once we recognize that governments are not run by benevolent policy makers, but by interested individuals, not only is politics introduced explicitly in the model, but also other forms of competition appear, which do not require mobility of voters. Local politicians need consensus to accede to, or to stay in, power. Citizens exploit this quest for consensus to force local governments that is, politicians - to compete to stay in office.

There is a plurality of ways in which governments can compete, as shown by Pierre Salmon (Chapter 2), who reviews the literature on horizontal competition. This literature contains important early contributions by Salmon himself, and the chapter deals with both mobility-induced competition and other types of competition.

Salmon does not question the assumption of costless mobility, as is occasionally done by others, but critically examines some of the results reached by the mobility literature. To take an example, one of the most common and politically significant conclusions of this literature is that mobility, whose effects epitomize globalization, deprives governments of autonomous choices. To be more specific, a tenet of this literature is that in a mobile world all taxes are benefit taxes and thus redistribution by government is no longer possible. Salmon's answer is that that is not necessarily the case, because individuals and firms have heterogeneous wants and preferences. In fact, redistribution can be Pareto optimal. According to Salmon, space is highly heterogeneous, meaning that various jurisdictions have different endowments of natural resources and of collective capital. In other words, there are locational rents which attenuate the constraint that all taxes have to be benefit taxes. Part or all of these rents can be used for redistribution to mobile poor.

Information is a crucial base for promoting competition. There are various components of this kind of competition. For example, voters can compare performances and can oust elected officials when not satisfied by the outcome of policies. Elected officials can also try to secure re-election by attracting, with targeted policies such as subsidized housing, groups of individuals from other jurisdictions who are likely to vote for them. Laboratory federalism has its roots in this literature, as does 'yardstick competition'.

Vertical competition takes places, furthermore, between central and subnational governments and can be viewed, as explained by Albert Breton 978184201515 
(Chapter 3), as a mechanism for the efficient assignment of functions among levels of government. Breton's chapter is quintessentially positive. His judgement is that the criteria elaborated by the theory for the assignment of responsibilities between layers of government have a very limited capacity to explain the real world of assignments. As an example, when an external shock takes place - let us imagine a technological innovation that increases the advantages of scale in relation to governments' policies - this should instantaneously lead to a reassignment of responsibilities (Breton calls these 'powers'). In fact, what happens in most cases is simply reorganization of activities. Reassignment is driven, particularly in countries with effective mechanisms of checks and balances, by vertical competition between layers of government. A basic assumption is that politicians maximize expected consent. If this is the case 'given tax prices ... politicians will endeavour to supply goods and services (including redistribution and regulation) to their citizens in quantities and qualities that match as closely as possible what these citizens desire'.

As is the case with markets, competition between governments maximizes consumer surplus. In Breton's words, intergovernmental vertical competition 'will forge Wicksellian connections' - that is, the link between the quantity of a particular good or service supplied by governments and the tax/price - 'as tight as possible so as to be granted the (expected) consent (vote) of citizens'. In other words, vertical competition generates assignments of policy responsibilities that reflect the comparative advantage of different tiers of governments.

Obviously, there are important constraints to its proper working. Institutions are extremely important. First, the structure of federal systems should be taken into account. Classical, two-tiered, federations are prone to competition between federal and state governments, but they reduce competition at the lower level, that is, between states and localities. The nature of the second chamber, in particular its mode of selection - popular vote or appointment by subnational government - can also be crucial in determining the extent of vertical competition.

Breton shows how distinct provisions of constitutions can shape competition, sometimes favouring the central government over subnational units, such as in the case of the 'commerce clause' inserted in the American constitution, or the recognition by the Canadian constitution of the distinct legal system of the Province of Quebec based on civil law. This is because laws designed by the federal government and concerning property and civil rights often require complementary legislation by provincial legislatures. Obviously, constitutional courts, including their composition and the length of tenure of judges, are a crucial element in shaping vertical competition. Finally, asymmetric arrangements would be hard to explain without recourse to vertical competition. They are a main, although neglected, feature of intergovernmental arrangements. This issue is taken up further in Congleton's chapter. 
In general, governments create a host of spatial interactions, forming an intricate web of relations, consisting of spillover of policies, of imitation effects, and of competitive behaviour. Local governments interact not only with the central government, but also among themselves. In fact, there are possibly more horizontal than vertical interactions. Federico Revelli (Chapter 4) deals with all these interactions and provides a comprehensive survey of the literature. Governments can interact with one another along three main channels: preferences, constraints and expectations.

In the presence of a direct preference interaction, the benefits of local public services provided in a jurisdiction spillover into neighbouring localities. This could be the case, for example, of public transport, education, training and environmental protection. Empirically, one should observe either positive or negative correlations among public expenditures as a result of the spillover, depending on the patterns of complementarity or substitutability. However, the empirical literature that investigates the size and direction of such spillovers is rather thin and does not provide definite results. Revelli feels that this could be caused by some other form of interaction taking place on the revenue side of budget.

Thus we immediately come across the second channel of interaction: the fiscal policy of a jurisdiction influences the size of a 'resource' in nearby localities and affects the budget constraint of other governments. Models of tax competition represent the classical example of the interaction of such indirect constraints. Tax competition theory yields two main empirical predictions. First, the desired tax rate in a jurisdiction depends on the tax rates set in nearby jurisdictions. Second, the tax base that locates in a jurisdiction is affected by the tax rate in that jurisdiction, as well as by those in neighbouring jurisdictions.

Finally, in the presence of expectations interaction, an action chosen by a government affects the expectations of the electorates of other jurisdictions. In the presence of an informational spillover from nearby jurisdictions, voters evaluate the performance of their own government relative to other governments, as dealt with in more detail in Salmon's chapter. In reality, each local jurisdiction interacts possibly with a large number of other jurisdictions and in most instances the influence of jurisdictions' policies will be reciprocal.

Revelli's chapter explores the empirical implications of the three forms of interaction sketched above, illustrates the main problems encountered by the empirical literature, and also draws implications for further research. Among the main problems Revelli mentions is the possibility that alternative theoretical models generate similar empirical predictions in terms of spatial reaction functions. Consequently, the estimation of a reduced-form interjurisdictional policy reaction function may not by itself allow sensible choices among competing theoretical hypotheses of spatial interaction, such 
as tax competition, expenditure spillovers and yardstick competition. Second, it is essential to avoid mistaking the presence of correlated shocks - a fairly common phenomenon when dealing with local government data - as evidence of actual strategic interaction by policy makers. For example, a reduction in the tax rates of a jurisdiction could be erroneously interpreted as a response to an analogous move in neighbouring jurisdictions, while in fact it might be generated by an increase in central transfers that affects each jurisdiction.

\section{Contractual, and contractarian, dimensions of intergovernmental relations}

Normative approaches to intergovernmental relations are characterized by a separation of functions, as in classical federations, and/or by hierarchy, as in unitary states. They have also relied on the assumption of the spatial uniformity of functional arrangements across governments at the same level. Separation and hierarchy do not exclude contractual relations, and these in turn generate asymmetric arrangements. In practice, the increasing use of intergovernmental contracts and reliance on asymmetric arrangements around the world are emerging as characteristics of present-day intergovernmental systems. This popularity is, on the one hand, a sign of the increased sophistication of intergovernmental relations, and on the other, possibly, of the increased political legitimacy of subnational governments. It would have been almost unimaginable in a traditional unitary state that municipalities could bargain with the central government and force it to come to formal agreements with them. This is, however, the real world and it has advantages, as shown in successive chapters by Roger Congleton, Reiner Eichenberger and Bruno Frey, and Paul Bernd Spahn.

Chapter 5, by Roger Congleton, is a close complement to Breton's treatment of vertical competition. In fact, Breton's final section suggested that competition would be conducive to different assignments for most subnational units. In other words, asymmetry is a consequence of vertical competition. Under asymmetric federalism or decentralization, government units at the same level have different allocative and regulatory powers. This is a common feature of federal and decentralized systems, although it has frequently been neglected. Congleton's chapter provides an explanation of why asymmetric arrangements arise and of their implications for political competition and service provision. Congleton's approach is based on bargaining between local governments and the centre. Symmetries emerge at the end of this process because subnational governments want to minimize the political risks of being associated with the central government in specific policies, or because they want to maximize their economic advantages. Congleton considers many cases.

The first, a rather frequent occurrence in history, is the case where the state is formed through the merging of existing provinces, cities and other forms of 
semiautonomous governments, as in the case of the United States, or the Netherlands. These units perceive mutual advantages from merging into a unique unity, such as scale economies and lower decision costs. Without the creation of the new state each distinct unit would need to bargain with each of the other ones to get the same results. There are also, however, political risks. A region could be excluded from the majority that governs the state and it could, as a consequence, suffer a net loss. More specifically, it would have to pay more than it would receive. Of course, there are institutions that reduce this risk, such as qualified majorities. Asymmetric assignment may be a better alternative: ' $[u]$ nder menu federalism, member states choose which services they will have produced centrally in much the same way that consumers select services from large firms in the marketplace'.

The second, opposite, case is that of over-centralization. Here the central government plays a pervasive role. For distinct reasons, some local governments perceive that the current level of service provision is underprovided in some sectors and that they could derive advantages if the responsibility for these sectors were devolved to them. An example could be public transportation. Local management could extend the transport network, reducing travel time and making the locality more attractive to individuals and firms. This would expand the tax base. Consequently, the same local units would be willing to pay compensation to the central government if powers were devolved to them.

The arguments developed by Congleton have many implications. First, asymmetric federalism or decentralization can emerge under a number of plausible circumstances. Second, bargaining between central and local governments determines the degree of centralization. Third, asymmetry is an efficiency-enhancing mechanism, provided that there are enough checks and balances at the local level to force local governments to promote the interests of their community.

Finally, most of the conclusions reached in Congleton's chapter match closely those of Breton. Assignment of responsibilities derives not from principles but from bargaining and competition between governments.

Chapter 6, by Reiner Eichenberger and Bruno Frey, presents the 'FOCJ' model, which the authors have proposed in the literature. It is a view of an ideal model of the spatial organization of the public sector, where the links between government units and territories are increasingly attenuated, if not severed. Their model, of which the real world offers an increasing number of (albeit partial) applications, refers to a federal/decentralized system whose constituent units have four distinctive characteristics. They are functional $(\mathrm{F})$, or more precisely mono-functional; they are responsible for a single policy and their size is determined according to the spatial impact of the policy for which they are responsible. As a consequence they have to overlap (O), meaning that 


\section{Handbook of fiscal federalism}

several functional jurisdictions operate on the same territory. Created by citizens' initiative they introduce competition $(\mathrm{C})$ in the public sector, but they have enforcement powers, implying that they are real jurisdictions $(\mathrm{J})$. In fact, what is needed is a constitutional provision sanctioning the right of citizens to create new jurisdictions. The FOCJ model rests basically on the distinction between provision and production, and on the increased possibilities of introducing competition even in monopolistic sectors, as shown by the privatization of natural monopolies such as telecommunications. As an example, a citizen of Bogotá may be part of mono-functional district that provides primary education to residents of the city. At the same time he/she will pay taxes to another jurisdiction that provides health care for a much larger area. A third jurisdiction will take care of road maintenance and has its headquarters located in a distant Colombian department. All these government units may make agreements with similar units located in the same country or in another one, as happens, for example, in the European Union.

Eichenberger and Frey's FOCJ idea has been widely discussed. The chapter included in this volume also provides an attempt to apply FOCJ to developing countries. Since FOCJ requires limited and flexible institutional arrangements, it is particularly suited, according to the authors, to developing countries, considering the weaknesses of their legal institutions. It represents a challenging suggestion that has to cope, however, with possibly low levels of citizen political participation in many countries.

In Chapter 7, Paul Bernd Spahn deals with a crucial innovation in intergovernmental relations: namely, substitution of rules and hierarchical commands by contracts. Since contracting is by definition consensual, it can take place, within the public sector, only among autonomous bodies with no hierarchical links. The use of contracts to order intergovernmental arrangements reflects the autonomy of decentralized governments, as well as the lack of information and sanctions available to a central government to enforce hierarchical arrangements.

Spahn compares the American and the German constitutions. The American constitution is based on the separation of responsibilities and functions between the federal and state governments. Initially, this represented a form of dual federalism, with the federal government operating almost completely independent from the states. However, growing interdependence between the federal government and the states has increased possibilities of conflict and opportunities for cooperation. Contracts can help to prevent conflict and generate cooperation.

The German constitution promotes concurrency of functions, typical of a corporatist tradition. In general, the federal government dictates policies and the states (Länder) execute them. However, the use of regulation and commands is resented by entities subject to these, and reduces accountability 
and transparency. Spahn argues that contracts can and should be used even in corporatist federal systems. In fact, they have been sponsored and popularized in Europe by the European Union, whose institutions, such as the bicameral system and the separation of legislation and execution, have shades of many of the German characteristics. The use of contracts has wide implications. For example, at the institutional level the most important is asymmetry of assignments. At the fiscal management level it increases the need for and importance of performance budgeting and of accrual accounting at the subnational level, and desirable as it might be, this might not be feasible in many countries, as argued by Ahmad, Albino-War and Singh later in the volume.

Contracts require not only autonomous government but also a wellstructured, 'third party' to facilitate their execution. They require an appropriate legal framework, with easy recourse to the courts and sanctions. In most countries, the specific legislation of contracts between public entities is missing as is an efficient judiciary for solving disputes. These requirements are problematic for many developing countries, although contracting has the same potential as in industrialized countries, as Eichenberger and Frey suggest in their chapter.

\section{Decentralization in developing countries}

Federalism and decentralization were traditionally found in rich countries with fully-fledged democratic systems. Latin America was an exception to this pattern, but federations come and go according to the shifting from democratic to autocratic rule. Federalization was promoted by Britain to provide a post-colonial framework to countries that had been created, particularly in the large and diverse countries (such as India and Nigeria) and also some smaller ones (such as the United Arab Emirates). Federations did not survive in some cases (British West Indies, Rhodesia and Nyasaland), or were subject to extreme stresses as in Nigeria. But they survived, even prospered, in other parts of the world (particularly in India).

The last two decades have witnessed the spread of decentralized governance in the developing world. New federations are being created. Some formerly unitary states, such as China, have gradually been transformed into effective multilevel systems, with lower levels of government enjoying a considerable degree of autonomy. Special legal arrangements were instituted for the returning colonies of Hong Kong and Macau. In Indonesia, a unitary constitution continues. However the reaction to decades of centralized rule has led to a formal incorporation of decentralization in laws enacted in 2000, and more recently to asymmetric arrangements for the natural resource region of Aceh.

These changing political and economic conditions require an adaptation of institutions and of the tools for their analysis as shown by Pranab Bardhan (Chapter 8). Decentralization is called to serve different objectives, such as 
poverty alleviation and improved service delivery. But problems remain and the evidence on improved service delivery and poverty reduction is inconclusive. Bardhan's chapter focuses on two logically related topics: (a) how decentralization improves policy outcomes in developing countries, and can thus generate growth and poverty alleviation; and (b) how the fiscal federalism literature has to be modified to provide a solid theoretical ground for policy making in this context.

There is no question that special characteristics of developing countries represent a challenge for decentralization and that the theory has to be modified to take these into account, in order to realize the presumed advantages of decentralized government. Bardhan argues that subnational units can derive limited benefit from mobility of individuals and firms, since they are greatly constrained by costs and social norms, such as exclusion of outsiders by tightly knit communities. High agency costs might accompany decentralization, given the potentially weak monitoring of bureaucrats and politicians. This enhances the likelihood that there will be elite capture, or that the benefits of public spending will be largely appropriated by the well-to-do or wellconnected, particularly in highly unequal societies. Moreover, the traditional fiscal federalism literature stresses the efficiency advantages of decentralization at the expense of equity considerations. For example, it assigns redistribution to the central level. In the context of poorer countries, the trade-off between efficiency and equity needs to be modified. More equality, or enhanced poverty reduction thorough local action, may generate more growth. It may also improve political accountability, since poverty reduction should lead to increased literacy and thus to a greater likelihood of popular control.

The benefits of decentralization are not obvious. Potentially, they can be substantial, but require appropriate policy making and a properly designed legal and institutional framework. This cautious evaluation is substantiated by Bardhan's survey of the literature. As expected, in most cases decentralization leads to increased devolution of resources to subnational governments. This may lead to an increased allocation of resources to sectors, such as education and health, that are strategic for alleviation of poverty. However, there is no convincing evidence that this has brought substantial improvements in the actual delivery of services, particularly to the disadvantaged groups in society. Some funds may be diverted by political and bureaucrat slack. These conclusions are also shared by the authors of the World Bank's World Development Report (WDR), on service delivery (see World Bank 2003), Junaid Ahmad, Shantayanan Devarajan, Stuti Khemani and Shehkar Shah. Chapters 8 and 10 both make policy suggestions about the appropriate legal and fiscal framework that is needed to turn decentralization into an effective instrument for improving governance.

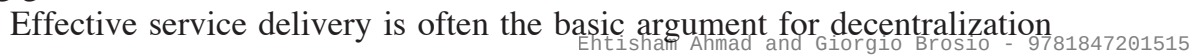


that is increasingly stressed by multilateral agencies, such as the World Bank and the United Nations Development Programme, and bilateral donors. Chapter 10, by Junaid Ahmad et al., examines the nexus between decentralization and improved service delivery, and is partly based on their work for the WDR. Their argument is that the attempts to bolster aggregate spending in the key areas have not had a significant impact, partly because the central government is unable to ensure that the funding actually reaches target groups, and possibly because central decision making might not match local preferences. The authors examine the administrative, fiscal and political aspects of decentralization and its linkages with improved service delivery, and review in greater detail the evidence on issues raised earlier, for example, in the chapter by Bardhan.

While central governments could conceivably vary service delivery to match local preferences, for example, by contracting out implementation and actual provision, this chapter argues that it is preferable for local governments to undertake this provision, as it would eventually lead to a better match of political power and incentives to ensure effective delivery, although the existence of 'elite capture' is acknowledged. The authors also recognize that the ideal sequencing of decentralization requires that the devolution of functions should come first, to be followed by financing and administration, but that this order might not be practicable in each case. There is some discussion of medium-term economic frameworks (MTEFs), a policy instrument favoured by the World Bank to provide a better intertemporal framework for decision making. However, MTEFs are resource intensive and few developing countries manage to implement these at the central level due to capacity constraints - but the detailed discussion of public financial management issues at the subnational level, including accounting, reporting and audit is left to another chapter (Ahmad, Albino-War and Singh). In this context, the advocacy for local government borrowing is tempered with the caveats that sequencing is important, and certain preconditions must be met before the borrowing would become 'productive'. However, Junaid Ahmad et al. argue that 'decentralization is not a one-off policy change; it is an ongoing process where the end point of accountable and efficient local governments may well take many decades to achieve'. In this framework, it would be difficult to know when to adjust objectives for greater decentralization - since any failures could be attributed to not having stayed the course. This is at variance with the more cautious approach taken by Bardhan.

Decentralization is taking place in industrial, developing and transition countries. Difficulties are magnified in developing countries with a centrally planned tradition, as in the case of China, Vietnam and, to a lesser extent, India. The continuing role of the central planners presents further challenges to decentralization. These challenges are analysed by Govinda Rao in Chapter 9. There is no doubt that Soviet-type central planning is the negation of federalism and 
that milder forms of planning also distort the operations of decentralized units. Central planning pertained largely to a past epoch, but has implications for the design of policy at the present time, and the chapter provides useful insights on the impact of excessive government intervention in the economy with decentralized jurisdictions. For example, an excessive emphasis on physical investment can lead to distortions in the allocation of resources, at the expense, for example, of maintenance of the existing capital stock. Investment plans that exceed available savings can lead, as in the case of India, to cuts in the amount of resources transferred from the central to subnational governments, inducing them to introduce, faute de mieux, highly distorting taxes, given the distribution of revenue-raising powers under the constitution. Even horizontal equity may suffer from excesses in investment.

Another negative feature of central planning is that it engenders a lack of transparency. In principle, the rationale of many decisions that concern subnational government is based on 'scientific method' and a wide national consensus. Thus transparency should be a major concern in this framework. In reality this is not, generally, the case where the central planners take the major decisions, as this distorts prices and signals for decision making. There is often a rigidity about transfers, and political influences make it difficult to adjust regional allocations and the lack of transparency induces inefficiencies in spending.

In countries moving from central planning to the market, there is generally a substantial reform agenda to make decentralization work.

\section{Design and reform of intergovernmental fiscal relations}

We turn next to the design issues that face policy makers in countries with multilevels of administration or government. This includes the assignment of spending functions for each level of government, and requirements for ownsource revenues. Given administrative constraints, it is likely that the major or more complex revenue sources will be assigned to or controlled by the centre. The possibility of vertical, as well as horizontal, imbalances across the same level of government feeds into the design of transfer systems. In all cases, the requirements for greater transparency and accountability and maintaining macroeconomic stability, place constraints on the way that public funds are budgeted, and spending reported and accounted for. Thus, governance issues are critical and are increasingly the focus of attention within countries, as well as of donors anxious to see that aid funds are used effectively.

Assigning responsibilities to subnational governments, assigning revenues to all levels of government, and supplementing local revenue with central government transfers are the basic ingredients of government operations in any multilevel system. These are at the same time the core of fiscal federalism theory.

We discuss each of these elements sequentially. 


\section{Expenditure assignments}

The assignment of expenditure responsibility is a crucial element of any intergovernmental system, since it determines at the same time the number of levels of government and the number of units within each level. As mentioned above, the problem cannot be solved in isolation. Local governments have coexisted with central authority in most countries, and the size and functions of local government have been determined by time, space, history and politics. However, economic considerations are important and cannot be neglected by policy makers. In Chapter 11, Bernard Dafflon assesses expenditure assignments in this framework.

According to the theory, once expenditures are assigned properly, the number of layers of government and the number of units comprising each layer should be automatically determined. Unfortunately, reality is more complex than the theory makes it out to be.

Characteristics particular to each country determine the number of layers and only partly explain the constitutional assignment of responsibilities. Within such a constrained framework, only 'reassignment at the margin of evolving functions and resources to existing political units' appears feasible. The chapter has a normative flavour, since it tries to single out the criteria that should guide the proposed marginal changes in existing assignments. However, the criteria neither derive solely from the economist's basket of tools, nor should they be imposed through a top-down decision making process.

Rather, Dafflon proposes a 'decentralization matrix', where a number of criteria for reassignment are listed as rows, and layers of government to which functions are attributable as columns. The matrix should be created with the contribution of all the stakeholders sitting at the negotiating table. This echoes the working of the constituent assembly proposed by Breton and Scott (1978), although it might be noted that Breton has successively moved towards a strictly positive approach to the assignment issue, as seen in his chapter in this volume. The initial list provided by Dafflon can be lengthened to bring into consideration the interests, the concerns and the hindsight of the various stakeholders.

There is also some flexibility concerning the number of columns, which relates to layers of government. Cooperation between distinct layers, and within the same layer, is becoming an increasingly popular (both in principle and de facto) characteristic of intergovernmental relations. As we have seen, its importance is also stressed in this volume by Eichenberger and Frey and by Spahn.

\section{Revenue assignments}

On the revenue side, the increase in mobility of persons, firms, and in general 
factors generates stimuli to competition but also some constraints, as shown in the chapter by Flavia Ambrosanio and Massimo Bordignon, and in the complementary chapter by John Wilson.

In Chapter 12, Ambrosanio and Bordignon deal with the main normative and positive components of the assignment of revenue. Various instruments are available, the most important of which are clearly taxes. The authors' main argument is that there is always a case for financing local governments with own-source taxes. Even in improbable cases, where all decentralized government units are identical in terms of the preferences and the economic conditions of their inhabitants and where no mobility exists, local taxes instead of revenue shares provided by the central government would still be preferable in order to generate incentives for greater subnational accountability. Local taxation would, in fact, introduce a limited amount of yardstick competition between local governments. As these limiting conditions are gradually lifted, the role of local taxes is enhanced. This is clearly the case when, for example, preferences differ among local governments about the desired level of local goods.

At the same time, lifting the restricting conditions reduces the choice of tax instruments. Consider the mobility of individuals and firms. If we take a Brennan and Buchanan (1980) approach, and assume that local politicians are totally rapacious and exploitative, then most mobile tax bases (for example, on income taxes or sales taxes, such as value-added tax: VAT) could be assigned to local governments. But there are a number of arguments against assignment of mobile tax bases to local governments that are reviewed in the chapter. When the Brennan and Buchanan assumption is dropped and politicians can be constrained by citizens and when localities (greatly) differ in their fiscal capacities, taxes cannot remain the only source of financing, unless society is ready to accept a (great) deal of inequality in the level of local service provision. Thus, the tax assignment must be designed jointly with a transfer system.

An interesting point is made by the authors with reference to dynamic issues. They point out that local taxation could play an important role in curbing expectations of soft budget constraints. This is because the threat by the central government not to intervene ex post to solve difficulties faced by local governments may simply be not credible ex ante, if the local governments do not have sufficient autonomy in determining their own revenues in order to take care of unpredictable events.

The chapter also presents a review of the arguments referring to the choice of distinct tax instruments and of the merits and demerits of alternative systems of revenue sharing between central and subnational governments.

The final section of the chapter is devoted to tax administration issues. While local administration clearly enhances the autonomy and accountability of decentralized government units, it would be important not to duplicate administration, or impose additional compliance burdens on the taxpayer for 
essentially the same tax bases. It is also important to be cognizant of administrative capacity limitations at the subnational level as well as of possible economies of scale in tax administration. These issues will affect the assignment, design and administration of the main taxes such as income taxes and VAT.

In Chapter 13, Wilson deals with tax competition. This is a topic that is receiving increasing attention in the literature and that lies at the crossroads of intergovernmental models of competition analysed by Salmon and Revelli and the tax assignment discussion by Ambrosanio and Bordignon.

The traditional literature posited that tax competition would almost inevitably lead to an inefficient level of local spending, because local tax rates were geared to attract tax bases from other jurisdictions. However, this literature concentrated solely on horizontal tax competition. Recent developments also address vertical competition and show that within this combined framework, tax competition is not necessarily welfare decreasing. This is the case when central government is assumed to maximize total welfare of the country and can use transfers to eliminate inefficiencies. Where central transfers cannot be provided, because of institutional limits, then competition leads to a welfare reduction. To appreciate the arguments, consider two distinct cases. The first is that of a very small country with even smaller regions that levy a tax on capital. If capital is mobile and there are no regional, that is, horizontal, externalities, then if one region raises its tax rates, capital will immediately fly to the rest of the world, not to other regions. No region would benefit from the move while the entire country will suffer from a decline in the supply of capital. There would thus be only a vertical externality, implying a lower than optimal level of public spending.

The second case is that of a big country, with a substantial weight in the world economy. In this case there would be no vertical externalities, but only horizontal ones, since the tax base for the whole country is fixed. In this case, horizontal externalities would lead to a lower than optimal level of public goods.

The relative size of horizontal and vertical externalities is also determined by the relative size of the different levels of government. Wilson's analysis provides interesting insights concerning global tax strategies. It shows, for example, that allocating more tax powers in Europe to the EU (supranational level), could increase the welfare of European citizens by making the EU more competitive relative to the United States.

The tax competition limits to revenue assignments makes this area a fruitful avenue for further research and policy development. 
important role in shaping intergovernmental arrangements. In classical federations, individual states were assumed to be self-sufficient. In unitary states, ad hoc grants were paid in exceptional cases to local governments in financial distress, but equalizing fiscal capacities was not considered to be a normal task of the central government. However, equalization or untied transfers are now an integral part of most intergovernmental systems. The magnitude of overall transfers, including both equalization transfers and special-purpose grants to meet central or donor objectives, generates problems for financing, requires transparency and proper institutions for allocation and finally consideration of their efficiency aspects, as illustrated in the chapter by Robin Boadway, and in that by Ehtisham Ahmad and Bob Searle.

Needs for public services and taxing capacities differ across various areas within a country, but it is often the case that poorer regions have greater needs as well as relatively limited resources. In the absence of central government intervention to provide transfers to the less well-endowed areas and/or to those with greater needs, households otherwise in identical circumstances will be treated differently according to the area of residence. The principle of horizontal equity would be violated. Efficiency in the allocation of resources would also be imperilled by movements of population to areas that are fiscally able to provide better services or to impose lower taxes. This is because these movements are not based on differences of productivity. In Chapter 14, Robin Boadway provides a thoughtful illustration of the equity and efficiency rationale for intergovernmental transfers.

While the grounds for establishing equalization transfers are clear, the degree of equalization to be introduced into the system is subject to controversy. First, in general, people have different views about equity. Second, satisfying horizontal equity may conflict with welfare maximization applied at the level of the whole country. This is the case, for example, when there are economies of scale in the production of local services. The principle of horizontal equity would imply that the central government should compensate with transfers the higher costs of smaller jurisdictions. In this case, the welfare maximization at national level would have to be sacrificed, because transfers would be paid not only to people in greater need, but also to those who might be less needy but happen to live in small and/or high-cost localities. Another difficulty arises when subnational governments choose different expenditure and tax policies which will result in equals being treated unequally. The central government could obviously correct these situations, but at the expense of local autonomy, which is a cornerstone of decentralized government.

There are two additional reasons mentioned in the chapter to establish equalization transfers. One is the implementation of national minimum standards, in areas such as education and health, which is the typical core of the functions, assigned to subnational governments in federal or otherwise highly 
decentralized systems, but is also at the same time crucial for determining the well-being of the entire population. The second reason is that transfers can serve to absorb temporary shocks in subnational governments' fiscal capacity. While there are arguments for the central government to intervene with transfers to absorb these shocks, there are similarly valid arguments for suggesting that subnational governments should, as much as possible, self-insure against these occurrences. The chapter provides a summary of the most recent literature on this subject.

The chapter also illustrates the rationale for transfers on efficiency grounds. As mentioned above, there is a possibility of a crucial inefficiency of migration in decentralized systems, because when people they decide to migrate, they do not take into consideration the impact of their decisions on the rest of the society.

Further, transfers can reduce the inefficiencies generated by use of distortionary taxes at the local level, the inefficiencies of local tax competition and finally the efficiency costs of local tax administration.

In Chapter 15, Ehtisham Ahmad and Bob Searle survey the main issues that countries face when they implement a grants system, and provide an array of examples on how problems are solved or aggravated through proper or improper decisions. The chapter assesses the design and implementation of both special-purpose and equalization grants, and complements the illustration of the rationale for equalization grants provided by Boadway.

The multiplicity of special-purpose grants in many countries is a cause for concern. In many respects, earmarked transfers limit or override the subnational decision-making power in areas of local jurisdiction. Moreover, in many developing countries, central governments lack the tools to monitor earmarked transfers, and the plethora of such grants, including from international donors, are simply not implementable. Yet, given limitations of capacity and the need to maintain minimum basic standards, many countries continue to rely on special-purpose grants that might exceed by far amounts for untied transfers that could be distributed on an equalization basis (including in advanced countries, such as Canada).

The point of departure of the analysis of the overall grants system is the legal framework for grants. Increasingly, grants are defined by constitutions. However, excessive detail and specification to appease worries of subnational governments, which are particularly evident in societies with distinct population groups, might engender macroeconomic inflexibility and the (undesirable) need to change the constitution if there is a change in economic circumstances. The objectives of an equalization framework are important, and in some countries one might expect to see these in the constitution. An example is to ensure that subnational governments will have the capacity to provide a similar level of services at comparable levels of own-tax effort. The 
standards for equalization are important - full equalization may not be fiscally feasible, or desirable. Averages used by some developed countries might be too low in developing countries trying to improve minimum living standards.

Ahmad and Searle's chapter proceeds by surveying the main steps for the design and implementation of grants systems, namely the determination of the total pool of resources to distribute, and the main approaches for the allocation of equalization transfers: that is, fiscal capacity and expenditure needs. Decisions are also needed on whether or not special-purpose grants should be taken into consideration in the estimation of equalization transfers. Specific consideration is given to the use of minimum standards for the determination of expenditure needs.

The manner in which untied grants are provided can have an important effect on the subnational government's incentives to manage their finances efficiently. 'Gap-filling' transfers to meet subnational deficits are perverse in that they vitiate incentives for efficiency. Also, in determining equalization transfers, care should be taken to avoid factors that are under the control of the recipient governments, as this might encourage distortions of information or other forms of gamesmanship. Increasingly, countries resort to independent agencies for grants administration, in order to separate politics from administration, and which could enhance the transparency of the whole process.

A major issue in grants implementation relates to data requirements. This is a problem that is mostly overlooked in the literature. When countries start with grants programmes, availability of data operates as a constraint to the articulation of the grants system, but it might be possible to begin with relatively simple formulations building on data that are generally readily available at the subnational level, including demographic characteristics. In general, data collection and use are crucial ingredients for the success of grants mechanisms.

\section{Governance and macroeconomic considerations}

One of the main messages of this Handbook is that competition between government units at the same or at a different level explains fundamental characteristics of the working of decentralized systems, and is potentially a crucial factor for their efficiency. In fact, a parallel can be drawn between the private and the public sectors. This parallel can also be extended to institutions of financial control and management aimed at guaranteeing the achievement of the efficiency potential. Transparent and well-conceived accounting systems and statements of accounts by private firms are crucial for ensuring control of management by owners. Control and auditing bodies are equally essential. The same applies to the public sector in general, and especially to lower levels of administration.

When governments are not benevolent, they are not necessarily disposed to ${ }_{\text {Ehlisham Anmad and G10rgio Brosio }}{ }_{9781847201515}$ 
follow transparent financial management practices, which are essential ingredients for the success of decentralization. Good governance and transparent use of public funds, together with a need to maintain overall macroeconomic stability in order not to jeopardize all jurisdictions of a country as a result of profligate behaviour of some subnational governments, are discussed in Chapter 16, by Ehtisham Ahmad, Maria Albino-War and Raju Singh. This chapter focuses on the analysis of crucial institutions for fiscal management at the local level and devotes particular attention to subnational debt.

There is a need for standardized information for policy making and to evaluate the results of the policy actions ex post, and for institutions to ensure full accountability at each level of government. Unfortunately, administrative capacity is in short supply, and the rush to decentralize might have to be constrained by what is feasible in terms of reporting. The authors argue that local political constraints on policy making and policy makers are likely not binding in the absence of relevant and timely information. Given the limited administrative capacities in most subnational governments, especially in developing countries, the chapter argues that attempts to move prematurely to results-based budgeting (that would be required in theory), could be counterproductive.

In essence, institutions and good practices that have been applied at the central level have to be replicated at the subnational levels. It is particularly important to institute standardized minimum requirements using international standards, such as those established by the International Monetary Fund's Manual of Government Finance Statistics (IMF, 2001), to facilitate comparisons across jurisdiction, to monitor all operations of subnational government and to establish an 'early-warning' system to alert policy makers to potential macroeconomic problems.

At the same time, one has to take into consideration that subnational units are inherently financially and administratively weaker than the central government, although there may be exceptions with large metropolitan areas (for example, the district of Bogotá in Colombia is generally more advanced than the central government in many respects). In addition, common-pool problems can arise, as in the case of borrowing, since each local government does not fully internalize the cost of its decisions. These difficulties have led many developing countries, particularly though not exclusively in Latin America, to slide into macroeconomic crises. A menu of options to address various borrowing and macroeconomic situations is developed.

This chapter thus complements many of the theoretical assertions made in the various chapters of this volume.

\section{Emerging issues}

Finally, Part IV deals with important emerging issues. The sharing of natural 2782701515 
resources among levels of government has become a burning issue that risks tearing apart countries if not properly solved, particularly in natural resourcerich countries. This is addressed in the chapter by Giorgio Brosio. Similarly, environmental protection is in most countries at the heart of the aspirations of the general public and involves all levels of government. Silvana Dalmazzone's chapter provides useful insights into this expanding field for research. Corruption is clearly not a new issue, but its possible impact on decentralization is a crucial factor to be considered. The opposing views on this issue are strongly held, and are summarized by Anwar Shah. And as Richard Bird and Robert Ebel show, decentralization can consolidate or imperil national unity, according to the institutions that are created.

The political economy approach to federalism and decentralization is a pivotal feature of this Handbook. Despite this qualification, the approaches presented have mainly been from an economist's perspective and written by economists. To complete the picture, the editors considered that a view from a political science perspective would be a useful complement to other chapters in the volume. This view is provided by Brian Galligan.

\section{The struggle over natural resources}

The sharing of revenue from natural resources among levels of government is a crucial issue for decentralized systems in natural resource-rich countries, such as Bolivia, Iraq, Nigeria and Indonesia. If this issue is not properly addressed, it could feed rivalries between the constituent units and put a great strain on national unity.

Rents from natural resources can be very substantial. When assigned to local jurisdictions, per capita rent amount can reach relatively high levels, generating substantial disparities with non-producing regions. Decentralization expands the role of subnational governments and makes them more vocal in demanding a share of the revenues generated within their jurisdiction. These issues are examined by Giorgio Brosio (Chapter 17), who presents, first, the main instruments for extraction and sharing rent among different layers of government. These can be various taxes, as well as non-tax instruments, such as auctioning exploration and exploitation rights, production-sharing agreements, and the acquisition of equity in natural resourceextracting enterprises. There can also be shares in overall revenues, or gross natural resource revenues, between different levels of government.

The chapter notes the trend for an increasing access by subnational governments to natural resource revenues, and examines arguments against and in favour of sharing the rent with subnational governments. Sharing gross petroleum revenues, for example, could subject subnational governments to the fluctuations in international prices that may place excessive strains on basic spending during price downturns, and waste and unsustainable spending 
during periods of rising prices. It also could exacerbate horizontal inequalities at the lower level of administration. The chapter also presents innovations in the practice of intergovernmental relations, mechanisms and solutions that can soften the political and economic impact of the assignment of natural resource revenues to subnational governments. The fluctuations could be avoided by assigning tax bases that might be invariant to prices - for example, taxes related to the volume of production - which would be more closely linked to compensation for environmental damage caused by the extraction of natural resources. To some extent, horizontal imbalances engendered by assignments of natural resources to subnational jurisdictions could be addressed through the transfer systems described in Part III.

\section{An example of decentralization and environmental concerns}

The protection of the environment is increasingly attracting attention at all levels of government, in response to a corresponding increase in the aspirations of the general public. The assignment of responsibilities in this area has stimulated the growth of an important literature that is reviewed in Chapter 18, by Silvana Dalmazzone, which concentrates largely on issues related to decentralization and the control of pollution. The message of the fiscal federalism component of this literature is straightforward: those forms of environmental protection that generate benefits contained within the boundaries of local jurisdictions present a strong case for decentralized assignment, whereas control of polluting emissions that tend to spillover local boundaries - and all the more global environmental problems - requires central government intervention.

However, there are many exceptions to this rule. One of these exceptions, favouring the assignment to the central government, is the importance of scientific knowledge. The environment is an area where policies rely heavily on scientific and technical information. A problem of scale may act as a constraint on the extent of feasible decentralization: small local authorities may not have the capacity to produce or even to process the existing information.

A large body of literature suggests two other reasons against assigning environmental regulation at the local level. The first of these reasons refers to 'the potential trade distortions that may arise from locally differentiated environmental standards'. The second one is that devolution of these responsibilities to the local level "could set in motion a competitive "race to the bottom" leading to inefficiently high levels of pollution'. The race to the bottom has attracted considerable attention, but it does not appear to be a phenomenon of significant empirical relevance. Pollution abatement costs are only one element among the many factors that impact on relocation of firms. Local governments have at their disposal other instruments to compensate firms for the imposition of these costs, as suggested in Salmon's chapter. 
Drawing from the specific literature on environmental economics, Dalmazzone provides supplementary warnings against decentralization of environmental responsibilities. First, the chapter mentions the complexity of ecological systems. It implies that policy decisions concerning, for example, the regulation of a specific kind of pollution in a given jurisdiction generally indirectly affects more than one ecological component, although the impact is sometimes lagged and difficult to predict. Second, there is a temporal dimension. Ecological functions have different temporal cycles: for some the cycle is seasonal; for others, it may be of longer duration. If governments at different levels use different intertemporal discount rates, this should be taken into account. If, for example, higher-level governments use lower discount rates in making their decisions, then the decentralized solutions would lead to an allocation nearer to efficiency for environmental resources whose ecological functions have shorter temporal cycles, and vice versa. Again this is largely an empirical matter and further enquiry is needed.

\section{Decentralization and corruption}

Anwar Shah (Chapter 19) examines decentralization and corruption: a crucial factor in determining the relative merits of decentralized against centralized government. A growing number of studies have recently been devoted to this issue, but there are no clear results. A segment of the recent literature views decentralization as an effective antidote to corruption because it should render local public authorities more accountable to citizens. Another stream initiated by Madison (Madison et al. 1788) in the Federalist Papers, holds the opposite view: federalism and/or decentralization disperses power in the hands of a larger number of public authorities and increases opportunities for extracting illegal advantages from government activities.

Shah's chapter provides a balanced view of this literature. It presents the main theoretical approaches starting with a typical Becker-type model and continuing with a brief account of the most recent contributions of the new institutional economics. The chapter also surveys the growing number of applied studies, which do not yet provide convincing evidence on the links between decentralization and corruption. This is possibly due, among other factors, to the lack of appropriate data. Most of the information on corruption that can be used for cross-country comparisons is built on surveys of business people dealing with public administrations. This offers a partial view of corrupt practices - excluding those that refer to citizens as consumers of public services. Moreover, most calculated indexes of corruption refer to the number of corrupt practices recorded and not their economic incidence. As decentralization increases the potential loci of corruption, it is likely to increase the number of corrupt practices. But the incidence of corruption should be the main focus of analysis. 
Shah's chapter provides useful and frank insights and also shows that the literature still has a long way to go to get definite results in this area.

\section{Maintaining national unity}

Federalization is an instrument of state creation. Decentralization is an instrument for maintaining states and to ease domestic conflicts in fragmented societies. This is an argument of Chapter 20, by Richard Bird and Robert Ebel. In fact, this tendency is seen increasingly across the world: Bosnia-Herzegovina, Spain, Ethiopia, South Africa and Iraq provide the leading examples. When the distinct components of a country, ethnic or otherwise, find it increasingly difficult to stay together, devolution to them of political autonomy becomes an obvious option. However, this is not entirely devoid of risk. In other words, decentralization could increase, rather than decrease, political instability. The design of decentralization is crucial, but very few generalizations emerge.

Interregional equalization comes at the top of the list. Divided countries stay together if each territorial component perceives that benefits outweigh costs. When income and wealth disparities are the main source of differences, or they combine with ethnic or other differences, regional redistribution is called for. It could, obviously, be complemented or substituted by interpersonal redistribution, but that would not always appease local elites. If brought too far, regional equalization becomes a factor of conflict, as in Germany, a solid federation with a well-developed welfare state.

Asymmetric decentralization is another possibility for addressing conflict situations. Bird and Ebel's analysis complements that of Congleton. In the latter's chapter, distinct regional preferences for policies do not have ethnic or cultural origins, but are mostly based on pure economic considerations.

\section{A view from political science}

Far from being obsolete, federalism is spreading across the world, albeit with evolving characteristics. It also provides an impetus and an instrument for solving challenges to governance coming from globalization. This is the main argument of Brian Galligan in Chapter 21, which concludes the volume from a constitutional and political science perspective. The chapter also singles out the distinct institutions that are essential to define federations and to ensure their survival.

Federations are strong decentralized systems, not because of the more extensive responsibilities assigned to subnational governments, but because of the high level of constitutional protection given to the jurisdictions that federate. When more protection is guaranteed, advantages from decentralization, such as competition, flow more easily. The three essential features of federations are: (i) a written constitution that is difficult to amend; (ii) a 
bicameral legislature; and (iii) judicial review. Federations are born out of agreements between constituents units submitted to popular referendum. A written text, the constitution, is a crucial pillar. It defines the spheres of autonomy of the federal government and of the federated jurisdictions. It also allocates responsibilities and revenues, or, in Breton's terminology, powers of government. Then, a crucial choice is faced by federations when the need for revision emerges: a lengthy participatory process, or a speedy process to ensure rapid adaptation of constitution mandates to the evolution of intergovernmental relations. Approval of constitutional amendments elaborated by the federal legislature by the constituent units of the federation, through a popular referendum or adoption by state legislatures, may be essential to maintain the vertical division of powers and the federal character. The process is clearly speeded up when the second chamber is selected according to the federal principle, as in Germany and South Africa, where the states (provinces) send their representatives to the second chamber.

The third institution, judicial review, is a channel for constitutional adjustment that does not require constitutional amendments. The problem here is that courts should never take decisions that deviate from the mainstream of political consensus. When conflicts among spheres of governments are brought to the Supreme Court, this implies that decisions should reflect the existing equilibrium of powers. But this has not usually been the case in a number of federations.

The interactions between political scientists focusing on institutions, and political economists examining how institutions interact and influence behaviour and economic outcomes, promises to be a fruitful one in further research in the area of intergovernmental fiscal relations.

\section{References}

Brennan, J. and J. Buchanan (1980), The Power to Tax: Analytical Foundations of a Fiscal Constitution, Cambridge University Press, Cambridge and New York.

Breton, A. (1965), 'A theory of government grants', Canadian Journal of Economics and Political Science, 31, 175-87.

Breton, A. and A. Scott (1978), The Economic Constitution of Federal States, University of Toronto Press, Toronto.

International Monetary Fund (IMF) (2001), Manual of Government Finance Statistics, Washington, DC.

Madison, James, Alexander Hamilton and John Jay (1788), The Federalist Papers, republished in Penguin Classics, 1987.

Montesquieu, Charles de Secondat, Baron de (1914), The Spirit of Laws, G. Bell \& Sons, London (public domain edition).

Musgrave, Richard (1959), The Theory of Public Finance, International Student Edition, McGraw-Hill, New York.

Musgrave, Richard (1961), 'Approaches to a fiscal theory of political federalism', reprinted in Musgrave (1986), Public Finance in a Democratic Society, Collected Papers, Vol. 2, Wheatsheaf Books, Brighton, UK.

Oates, Wallace (1972), Fiscal Federalism, Harcourt-Brace, New York. 
Olson, Mancur (1969), "The principle of "fiscal equivalence": the division of responsibilities among different levels of government', American Economic Review, 59, 479-87.

Tiebout, Charles (1956), 'A pure theory of local expenditures', Journal of Political Economy, 64, 416-24.

World Bank (2003), The World Development Report 2003, Washington, DC. 
Ehtisham Ahmad and Giorgio Brosio - 9781847201515 Downloaded from PubFactory at 04/26/2023 $09: 04: 13 \mathrm{AM}$ 